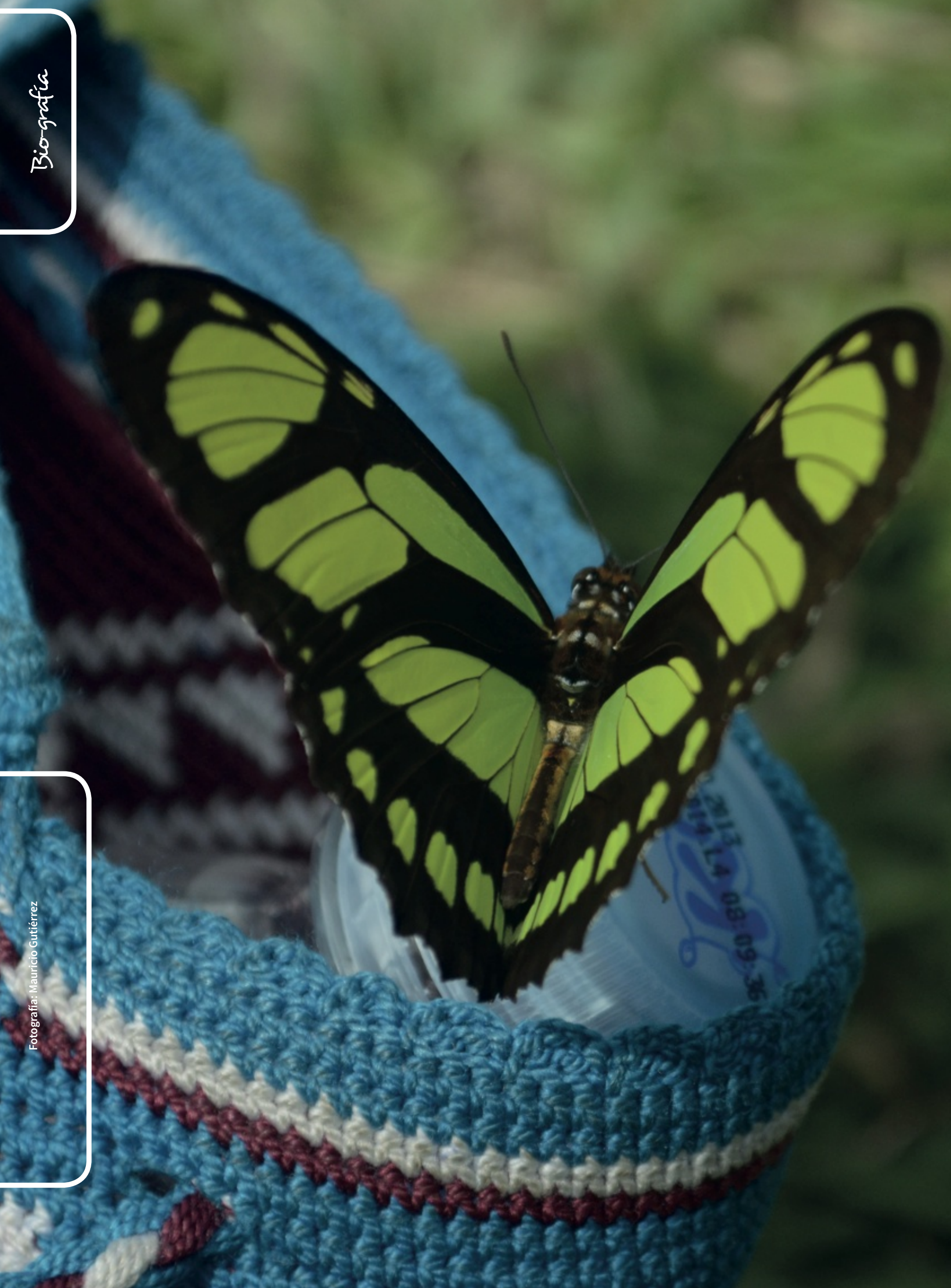




\title{
LA VIDA Y LOVIVO PARA LOS INGA UN ACERCAMIENTO A OTRA REALIDAD EDUCATIVA
}

\section{Life and i live for Inga an approach to another reality education}

Fecha de recepción: 16 de agosto de 2013

Fecha de aprobación: 013 de diciembre de 2013

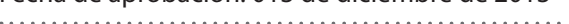

Ángela Patricia Cárdenas Toro ${ }^{1}$

\section{Resumen}

El artículo presenta los resultados de la investigación de práctica pedagógica integral ${ }^{2}$ cuyo propósito fue identificar el contenido de las representaciones sociales (RS), acerca de lo vivo y la vida en los saberes de los mayores, orientadores ${ }^{3}$ y estudiantes de la institución inga Yachaikury, ubicada en la jurisdicción de Yurayaco, San José del Fragua Caquetá, a partir de la vivencia con la comunidad y el acompañamiento pedagógico durante cuatro meses.

La investigación se hizo a través de una metodología cualitativa para conocer el contenido de las RS, y los instrumentos para recopilar la información fueron diario de campo, observaciones participantes, conversatorios, recorridos territoriales, participación en carnavales y rituales propios de la comunidad, participación en actividades dentro y fuera de la institución y entrevistas.
Se logró identificar unidades de información de las que se infieren que lo vivo y la vida son que son dos categorías inseparables e interconectadas y que su comprensión de mundo se articula con un cúmulo de representaciones que cobran sentido con su cosmovisión como eje transversal de la práctica. La vida y lo vivo para el indígena inga es poder trabajar la tierra como un elemento vivo del territorio que le proporciona el sustento y una posibilidad de pervivir física, cultural y biológicamente en el mundo de hoy.

\section{Palabras claves}

Representaciones sociales, vida, vivo, interculturalidad, saber inga.

1. Licenciatura en Biología. Universidad pedagógica Nacional Emailapoyosed.angelacardenas@gmail.com. Línea de investigación Configuración de los Conocimientos Acerca de lo Vivo y de la Vida. Grupo de investigación Enseñanza de la Biología y Diversidad Cultural. Asesora de práctica: Leidy Marcela Bravo Osorio. Bogotá D.C, 29 de Septiembre de 2013.

2. La práctica pedagógica, según el Art. 11 del acuerdo 035 del 2008, propuesto en el reglamento académico de la Universidad Pedagógica Nacional, se plantea como un espacio de reflexión-acción e investigación, en torno a la innovación, indagación y recontextualización de los saberes desde enfoques éticos, estéticos, cognitivos, pedagógicos y didácticos, en función de la formación profesional e integral del practicante. Se realiza en dos niveles con una intensidad horaria de 15 horas semanales o en un solo nivel integral donde el estudiante dedica tiempo completo y no inscribe ningún otro espacio académico (reglamento de práctica, 2010).

3. Los mayores son las autoridades tradicionales, los abuelos y abuelas o sinchikuna o lachaikuna de primera generación, también hay mayores hijos de abuelos de segunda generación. Los orientadores son los etnoeducadores o iachachidurkuna encargados del proceso educativo desde el conocimiento propio y de las otras culturas (Proyecto Etnoeducativo, 2012). 


\section{Abstract}

The article presents there search results of comprehensive teaching practice whose purpose was to identify the content of social representations (RS), about the living and life in the knowledge of Elders, counselors and students of the institution Inga Yachaikury, located in the jurisdiction of Yurayaco, San José del Caquetá Fragua, from the experience with the community and educational support for four months.

There search was done through a qualitative methodology for the content of RS, and tools to gather information were diary, participant observations, conversations, land tours, participation in ritual sown carnivals and community participation in activities inside and outside the institution and interviews.

It was possible to identify information units which infer that the living and life are two inseparable and interconnected categories and their understanding of the world is articulated with a cluster of representations that become meaningful with their world view as a central focus of practice. The life and live for indigenous Inga is able to work the land as a living element, the territory provides sustenance and a possibility of physical, cultural and biologically survive in today's world.

\section{Key Word}

Social Representations, Life, Live, Interculturalism, Knowledge Inga.

\section{Introducción}

Partiendo de la necesidad que se tiene de replantear, renovar y reconstruir las prácticas de la enseñanza de la biología, y de que el maestro en formación conozca y vivencie distintos escenarios educativos, cuestionando la influencia de diferentes instituciones normalizadoras, limitantes y rígidas que priorizan elementos políticos, administrativos y normativos(Castaño, 2010), se genera una propuesta de investigación cuyo propósito es dar otro sentido a la enseñanza de la biología desde una práctica en contexto que responda a las diversas realidades que se viven en Colombia, y que se derive en un proceso de construcción colectiva de conocimientos y saberes ${ }^{4}$ en

4. Los conocimientos para los ingakuna hacen parte de los saberes, no representan lo mismo, en la medida en que se van adquiriendo a partir de las relaciones sociales que se establecen y se convierten en saberes cuando se configuran en la práctica como eje central para lograr un determinado aprendizaje. torno a problemáticas propias de cada una de las comunidades, grupos sociales y al conocimiento biológico. Es claro que tal conocimiento debe ser puesto a disposición de todas las comunidades independientemente de sus niveles educativos y formas de enseñanza en un país que se asume como biodiverso, pluriétnico y pluricultural, resultado de organizaciones y movilizaciones indígenas que lideraron el proceso de reafirmación del principio y derecho de Identidad que generó que la constitución del 1991 reconociera la diversidad cultural y con ello la identidad cultural que lleva a la reflexión sobre propuestas educativas contextualizadas y pertinentes para las diferentes comunidades étnicas de Colombia (Ministerio de Educación Nacional, men, 2009).

Los conocimientos son producidos en un contexto específico que ha sido producto de una historia y de unas relaciones sociales y tienen diferentes grados de apropiación y formas de socializarse (Castaño, 2010). Hoy en día se evidencia que existen individuos cuyo poder lo potencializan para rivalizar e imponer conocimientos y formas para transmitirlos. En el marco de la educación actual existen imposiciones de conocimientos o formas de explicar el mundo que, desde occidente, están poniendo en condición de subalternidad a otro tipo de saberes surgidos en condiciones culturales propias, continuando con el proceso colonial que desmerita otras formas de concebir el mundo y aprender sobre él, acrecentando paradigmas de control, de homogenización, de subordinación y destrucción de territorios y cosmovisiones de grupos humanos, para responder al concepto de desarrollo económico resultado de la ola globalizadora y el posmodernismo que llega hasta los lugares más recónditos del país (Castaño, 2010, p. 573).

Colombia es un país con diversidad de gente, grupos o comunidades, razas, de familias lingüísticas y cosmovisiones; en cada una de estas se han construido, se tejen y se siguen tejiendo una gran riqueza de saberes y conocimientos que son ignorados en los programas de educación. En este país no se ven planes de estudio ni estrategias que lleven al reconocimiento de la diversidad étnica y cultural de los diferentes contextos; aun cuando existen programas de Etnoeducación, un acercamiento profundo a estas propuestas y a los requerimientos del Ministerio de Educación Nacional hacen pensar que lo que realmente se busca es la homogenización de la forma de concebir el mundo y la normatización a través de instituciones influenciadas por elementos de saber y de poder que desconocen los saberes construidos desde hace muchos años por pueblos y culturas originarias del país. 


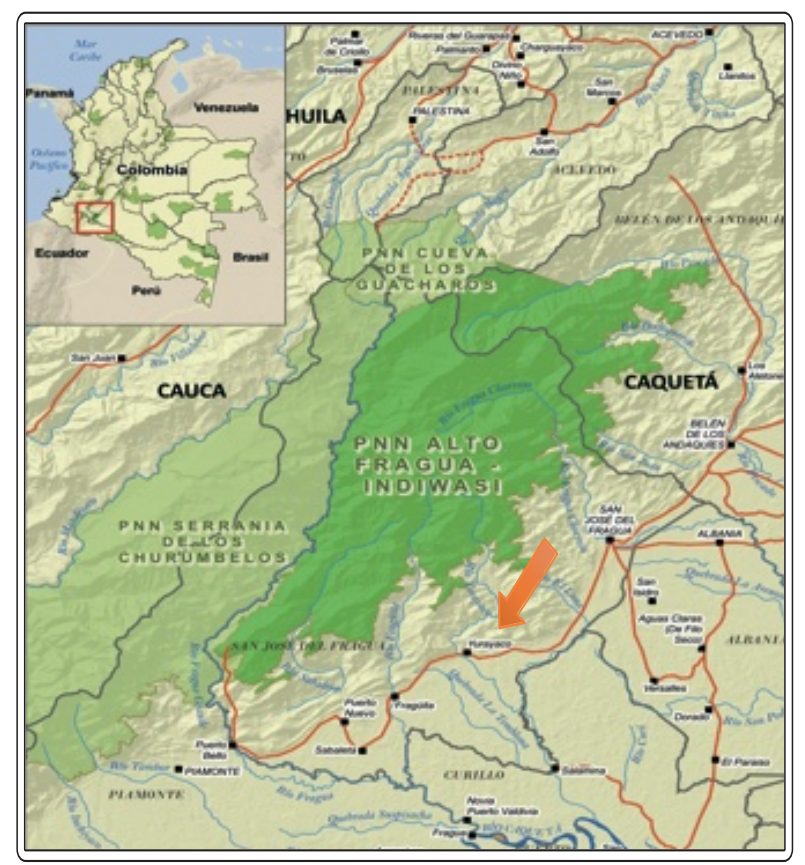

Gráfico 1. Ubicación geográfica de la Institución Educativa Inga Yachaikury. Colombia, Departamento del Caquetá, Municipio de San José del Fragua, Inspección de Yurayaco. Resguardo Indígena Yurayaco. Fuente Mapas Google, 2014.

Es así como la Institución Educativa Inga ${ }^{5}$ Yachaikury perteneciente a la Asociación de Cabildos Tandachiridu Inganokuna, ${ }^{6}$ que quiere decir "todos unidos por un mismo pensamiento" ubicada al suroccidente del Caquetá, en la inspección de Yurayaco, perteneciente al municipio de San José del Fragua, Colombia, como se indica en el gráfico 1, lugar en el que se desarrolló investigación, se presenta como un espacio donde se lleva a cabo una forma de educación diferente en el que existen

5. "El principal asentamiento del Pueblo Inga es el Valle de Sibundoy, localizado en lo Alto del Rio Putumayo a 2.200 metros sobre el nivel del mar, se encuentran ubicados en varios lugares del territorio nacional, como Aponte-Nariño; Bota Caucana; Medio Putumayo, Bajo Putumayo, Alto Putumayo y Caquetá, en este último, está ubicado el resguardo de Yurayaco y ocho resguardos más, aunque no se debe desconocer que hay otras familias de esta comunidad en ciudades como: Cali, Barranquilla, Medellín y Bogotá. A nivel histórico por la ola de expansión que sucedió en los años de 1900, en la zona de Putumayo, algunas familias decidieron emigrar al Caquetá defendiendo su territorio, alejándose un poco de las comunidades de origen" (Ministerio de Educación Nacional, Modelo etnoeducativo del pueblo Inga, (2012-2013).

6. Cabildo hace referencia a la forma de organización y de gobierno impuesta por los colonizadores a las comunidades indígenas y que luego ha sido apropiada por estas comunidades y utilizada como figura legalen sus procesos de lucha y resistencia. Está conformado por un gobernador mayor, un alcalde mayor y un alguacil mayor. Un resguardo es la figura de posesión de tierras por una comunidad indígena. maneras distintas de ver la vida y de entender el mundo y los fenómenos que lo constituyen. El proceso de educación propia está fundamentado en su plan de vida. ${ }^{7}$

La institución es privada para la formación de Ingakuna, cuenta con la aprobación de estudios de la Secretaria de Educación del Departamento del Caquetá, pero no es reconocida como institución de educación indígena y, por tanto, no cuenta con recursos del Estado para subsidiar los procesos educativos que se llevan a cabo. Actualmente, los orientadores $\mathrm{y} / \mathrm{o}$ etnoeducadores son contratistas, decreto 2500 de 2012, pero durante la estancia en la institución se evidenció que no se realizó la contratación a tiempo y que aun así la institución seguía trabajando en condiciones de autosostenibilidad, vocación, compromiso y voluntad de las personas que llevan el proceso educativo. Este colegio busca promover la supervivencia física y cultural de los Ingakuna, así como la reconstrucción de sus territorios, cultura y economía.

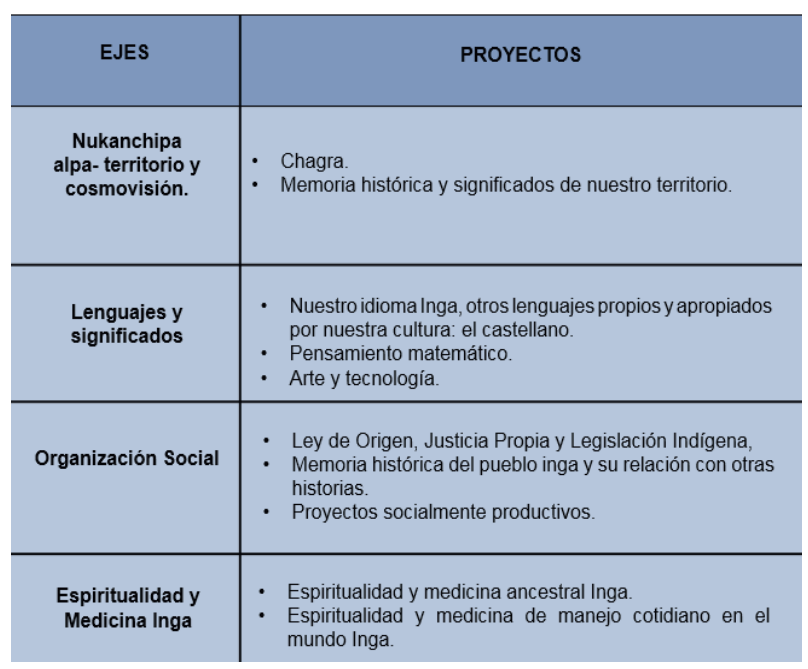

Gráfico 1. Matriz de ejes y proyectos de educación propia. Comunidad inga del Caquetá. Fuente: Modelo Etnoeducativo, 2012.

La comunidad Inga parte de la reflexión sobre las maneras de la educación convencional y el impacto en su cultura, afirmando que interfiere en las formas y contenidos de la educación Inga, causa deserción escolar por el extrañamiento de espacios significativos en su mundo, suplanta a los mayores, médicos tradiciona-

7. El plan de vida es el núcleo de organización y participación donde están consagrados los objetivos y metas y a la vez es la fuerza motivadora del bienestar, la convivencia y el desarrollo de los Inga. Para los Ingakuna la vida y la cultura son una misma cosa, esta idea es la base de dicho plan en relación con el territorio, la vivencia con la tierra, lo que en su lengua seria Nukanchi Kaugsay luiai, —nuestra forma de pensar la vida(Proyecto Etnoeducativo, 2012). 
les y a la comunidad como educadores de las nuevas generaciones y hasta el momento no ha logrado dar sentido a la realidad concreta a la que se enfrentan. (Proyecto Etnoeducativo del Pueblo Inga, 2012).

El proceso educativo también está orientado por el proyecto y modelo etnoeducativo, propuesta que viene siendo formalizada desde el año 2008, en el marco de la política pública de Etnoeducación en Colombia. Metodológicamente, su modelo se estructura en ejes como se muestra en el gráfico 2 y se desarrolla desde actividades cotidianas que se abordan como proyectos pedagógicos de investigación, entendida esta como una estrategia que actualiza y afianza los procesos de aprendizaje propio y la interculturalidad, profundizando en lecturas de sus realidades para transformarlas (Ministerio de Educación Nacional, 2012). Esta comunidad está haciendo de la educación el medio más efectivo para rescatar y fortalecer su identidad cultural y favorecer a largo plazo la conservación de la diversidad cultural y biológica de su pueblo.

El objetivo central de esta investigación es comprender las representaciones sociales sobre lo vivo y la vida, a partir de los saberes de los mayores, orientadores y estudiantes de la comunidad Ingakuna de la Institución Educativa Inga Yachaikury y el Resguardo Yurayaco. De ahora en adelante, en el texto enunciaremos a las Representaciones Sociales con la sigla RS, y la definición que se tendrá en cuenta para esta investigación es "una unidad organizada y jerárquica, de juicios, de actitudes y de información que un grupo social dado elabora a propósito de un objeto". Abric (citado por Araya, 2002, p. 26) afirma que "las RS resultan de un proceso de apropiación de la realidad, de reconstrucción de esa realidad dentro de un sistema simbólico. Ellas son interiorizadas por los miembros del grupo social, y luego engendradas y compartidas colectivamente". Las RS fueron el camino metodológico para entender el saber inga y el conjunto de conocimientos, creencias, valores, actitudes y aptitudes que lo conforman y que son compartidos por esta comunidad indígena a partir de las explicaciones que dan a los distintos fenómenos que les rodean.

Los objetivos específicos están encaminados a la identificación de la RS, a establecer la relación de dichas representaciones sobre la vida y lo vivo con las prácticas agrícolas ancestrales y finalmente analizar y reflexionar sobre la reconfiguración de la enseñanza de la biología, a partir de la comprensión de las diversas manifestaciones de la vida y de lo vivo y su relación con la prácticas agrícolas ancestrales, involucrando los conocimientos tradicionales ancestrales del pueblo inga con otros conocimientos como el disciplinar biológico desde una perspectiva intercultural.
Abric (citado por Araya 2002) afirma que "el abordaje de las representaciones sociales posibilita entender la dinámica de las interacciones en contextos diversos y aclarar determinantes en las prácticas sociales, pues la representación, el discurso y la práctica se generan mutuamente" (p. 12). Araya (2002), por su parte, dice que las RS "son una herramienta muy valiosa porque ofrecen un marco explicativo acerca de los comportamientos de las personas estudiadas que trasciende al marco cultural y a las estructuras sociales más amplias" (p. 9).

Es así que las RS son una modalidad de conocimiento común y colectivo y se relacionan con los principios pedagógicos que fundamentan a la Institución y la comunidad inga:

El trabajo colectivo cuyo principio orientador es la reciprocidad, "ninguno de nosotros sabe tanto como todos juntos" pensamiento que corresponde culturalmente con los conversatorios, asambleas y mingas de socialización de saberes, regidas por los principios Uiasunchi, luiarisunchi, Rurasunchi, lachaikusunchi escuchemos, pensemos, hagamos y aprendamos-. Este es el camino de apertura para la investigación, los conocimientos se construyen a partir de experiencias cotidianas, individuales y colectivas. (Proyecto Etnoeducativo del Pueblo Inga, 2012, p. 21)

Esta propuesta investigativa es de gran importancia para la reconfiguración de prácticas pedagógicas y para la formación de los futuros docentes de biología, en la medida en que los resultados y experiencias pueden aproximarse a caracterizar aspectos epistemológicos y ontológicos del conocimiento acerca de lo vivo y de la vida en un país que se reconoce como biodiverso, pluriétnico y multicultural; también permite caracterizar elementos pedagógicos y didácticos que puedan contribuir a la construcción de propuestas para la enseñanza de biología en contextos con características particulares; $y$, sin lugar a dudas, es una iniciativa para propiciar procesos educativos en enseñanza de la vida y lo vivo desde un enfoque intercultural, como un plataforma para interpretar la realidad del otro y establecer diálogos en horizontalidad con interacciones en igualdad de oportunidades.

La formación de un licenciado en biología busca el desarrollo humano integral, y para ello es necesario que los estudiantes desarrollen un conjunto de acciones basadas en la diversidad de aspectos éticos, políticos, morales, sociales, ideológicos e intelectuales en los diferentes contextos para la consecución de su profesión, que le permitan el desarrollo de un pensamiento crítico y reflexivo sobre lo que observa, experimenta y analiza, 
para luego realizar propuestas que lleven a la interacción con los educandos y con su realidad social y cultural, motivando hacia el desarrollo de proyectos viables para la innovación y mejoramiento de la calidad educativa del país, de esta manera la investigación posibilita la interacción en contextos diversos, dando lugar al dialogo y al reconocimiento de otras formas de comprensión del mundo (Departamento de Biología, 2012)

\section{Diseño metodológico}

La intención y la oportunidad de desarrollar la práctica integral con esta institución se hizo posible gracias a la apertura de la misma para intercambiar experiencias y promover el fortalecimiento de su colegio, el proceso etnoeducativo y la comunidad con otros conocimientos, pues para ellos es claro que la pervivencia parte del conocimiento de los mayores como primera medida, de la acciones que realizan en el territorio y de los conocimientos que les puedan brindar las otras culturas.

El desarrollo de la investigación se llevó acabo en la participación de diferentes actividades que se realizaban en la institución y los resguardos pertenecientes a la asociación de cabildos Tandachiridu Inganokuna, como: el desarrollo de actividades académicas con los estudiantes, participación en mingas, ${ }^{8}$ siembras, reuniones comunitarias, participación en el Atun puncha, Wata o Kalusturinda, ${ }^{9}$ ceremonias de ambiwaska, ${ }^{10}$ diálogos y consejos en la madrugada, observaciones de clases, conversatorios con mayores, orientadores y estudiantes, participación en trabajos de la chagra, ${ }^{11}$ (Comunicación Personal, Mutumbajoy, E. Abril de 2013), en el vivero, en el proyecto de abonos orgánicos y en los recorridos por el territorio, donde los sujetos investigados manifestaban nociones, ideas, actitudes, creencias y aptitudes en los distintos procedimientos para enseñar saberes,

8. Reunión de actores de la comunidad para realizar un trabajo en conjunto.

9. Carnaval o fiesta del perdón. Tres días en el que se agradece a son de cantos y danzas, comidas y bebidas tradicionales por el año que acaba y el que comienza y se perdona por lo negativo. Se realiza tres días antes del miércoles de ceniza (Modelo Etnoeducativo, 2012-2013).

10. El mundo Inga se ritualiza en ceremonias en que a través del Ambiwaska, se establece comunicación con otros mundos, desde ellos se coloca en armonía la realidad, por eso son llamados de la cultura milenaria del yagé o Ambiwaska (Modelo Etnoeducativo, 2012-2013).

11. Es definida por los orientadores de Yachaikury como "el rio, el bosque, la quebrada, la laguna, el rastrojo; el espacio que nos rodea donde se siembra el alimento, remedios, frutas, arboles artesanales y maderables de donde nos beneficiamos todos" (Comunicación personal, Mutumbajoy, E. Abril de 2013). preparar la tierra, sembrar, el uso del calendario lunar, el consejo de los mayores, entre otros conocimientos tradicionales para lograr buenas cosechas y favorecer el sustento propio, el cuidado de la madre tierra -Nukanchipa Alpa-y de la vida propia.

Para la investigación se hizo necesaria una metodología de corte cualitativo, pues en su sentido amplio, según Taylor y Bogdan (1986), citado por Rodríguez, Gil, y García (1996), la consideran como "aquella que produce datos descriptivos: las propias palabras de las personas, habladas o escritas, y la conducta observable", donde el investigador cualitativo ve al escenario y a las personas desde una perspectiva holística; trata de comprender a las personas dentro del marco de referencia de ellas mismas, es sensible a los efectos que causa sobre las personas objeto de estudio; suspende o aparta sus propias creencias, perspectivas y predisposiciones y hace de su investigación un proceso de compartir y vivir en la comunidad y como la comunidad y los sujetos investigados viven. Lo cualitativo en la investigación pretendía acercarse al aspecto constituyente del pensamiento, es decir, los procesos, donde el énfasis está en el proceso social, en el contenido de la RS y no en los mecanismos cognitivos de las mismas.

El proceso para la interpretación de las RS se hizo desde una perspectiva hermenéutica, cuyo ideal principal desde varios pensadores es:

Todo conocimiento está de alguna u otra manera mediado por la interpretación y que nuestra realidad es el producto de dicha interpretación, esto es, que nunca nos las tenemos que ver con el mundo "real" sino con interpretaciones de él; por lo cual, en lugar de tratar de explicar al mundo (especialmente al social), deseamos comprenderlo. (Monzón, 2011, p. 10).

En esta postura el ser humano es visualizado como un productor de sentidos, se focaliza en el análisis de las producciones simbólicas, de los significados, del lenguaje y de todo aquello que pueda ser interpretado para construir una explicación de una determinada realidad, en este caso la realidad de la comunidad educativa inga Yachaikury.

Siguiendo a Araya (2002) quien afirma:

Para acceder al contenido de una representación, el procedimiento clásico utilizado es la recopilación de un material discursivo producido en forma espontánea (conversaciones, diálogos), o bien, inducido por técnicas interrogativas (entrevistas abiertas). Los discursos cristalizados fotografías, grabaciones, pueden ser también objeto de análisis. (p. 49) 
Los materiales para la recopilación de la información fueron un cuaderno de campo para escribir diferentes apreciaciones de las actividades realizadas, cámara fotográfica, grabadora de voz, documentos escritos sobre la comunidad y su proceso de educación. Y los espacios o instrumentos fueron conversaciones abiertas, entrevistas abiertas, elaboración de dibujos y soportes gráficos, y recorridos territoriales con los mayores, orientadores y estudiantes.

Para el manejo y sistematización de la información recopilada se recurrió a la interpretación, análisis y reflexión de lo que dicen los mayores, orientadores y estudiantes, ya sean textos escritos, grabados, pintados, filmados, transcripción de entrevistas, discursos, protocolos de observación y documentos.

Independientemente de su modo de producción y teniendo en cuenta la primera línea de investigación de las RS, según Pereira de Sá (citado por Araya 2002), "la escuela clásica desarrollada por Denise Jodelet, en estrecha cercanía con la propuesta de Moscovici, que propone que las RS son pensamiento constituyente (procesos) y constituido (productos)" (p. 47), es decir, al ser parte de la realidad social, estas contribuyen a su configuración y producen en ella una serie de efectos específicos y así mismo construyen un objeto del cual se hace una representación.

La RS han sido abordadas por la escuela clásica, desde dos enfoques o líneas de investigación, estos son el procesual y el estructural. Esta investigación se aproximó a comprender y explicar el enfoque procesual de las RS en torno al objeto de estudio propuesto con la comunidad de la institución educativa inga Yachaikury, cuyo fundamento teórico y epistemológico descansa en postulados cualitativos y privilegia el análisis de lo social, de la cultura y de sus interacciones, y para conocer o establecer un RS es necesario determinar dos aspectos de la información recopilada: lo que se sabe (la información); lo que se cree o cómo se interpreta (el campo de la representación $\left.{ }^{12}\right)$.

\section{Resultados}

Se presenta a continuación el instrumento que permitió la organización de la información recopilada para su interpretación y comprensión. La información fue sistematizada en dos matrices donde se organizaron los datos recogidos a partir de observaciones en las clases, preguntas abiertas, conversatorios, diálogos, actividades y demás instrumentos usados en el proceso investigativo con los mayores, orientadores y estudiantes para identificar las representaciones sobre el objeto de estudio, la vida y lo vivo,

La matriz 1, se desarrolló a partir de una actividad que consistía en que los estudiantes realizaban un dibujo sobre lo que para ellos era lo vivo y la vida y luego verbalizaban. Después otro dibujo con algo con lo que pudieran relacionar las dos categorías. Esta matriz muestra las categorías que hacen referencia al objeto de estudio (vida-vivo); unidades de información (representaciones sociales) en la que se encuentran textuales las verbalizaciones (información recopilada) estudiantes, y finalmente una subcategoría que surge y se establece durante la investigación como eje transversal al objeto de estudio.

12. El campo de la representación se entiende como las actitudes, valores, opiniones, imágenes, creencias, conocimientos y vivencias que se infieren de una representación social (Araya, 2002, p. 49). 
Tabla 1. Matriz de categorización de información de estudiantes de la ie inga Yachaikury

\begin{tabular}{|c|c|c|}
\hline CATEGORIA & $\begin{array}{l}\text { UNIDADES DE INFORMACIÓN } \\
\text { (Representaciones Sociales) }\end{array}$ & $\begin{array}{c}\text { SUBCATEGORIA: } \\
\text { Relación Prácticas Agrícolas } \\
\text { Ancestrales }\end{array}$ \\
\hline 1. VIVO & 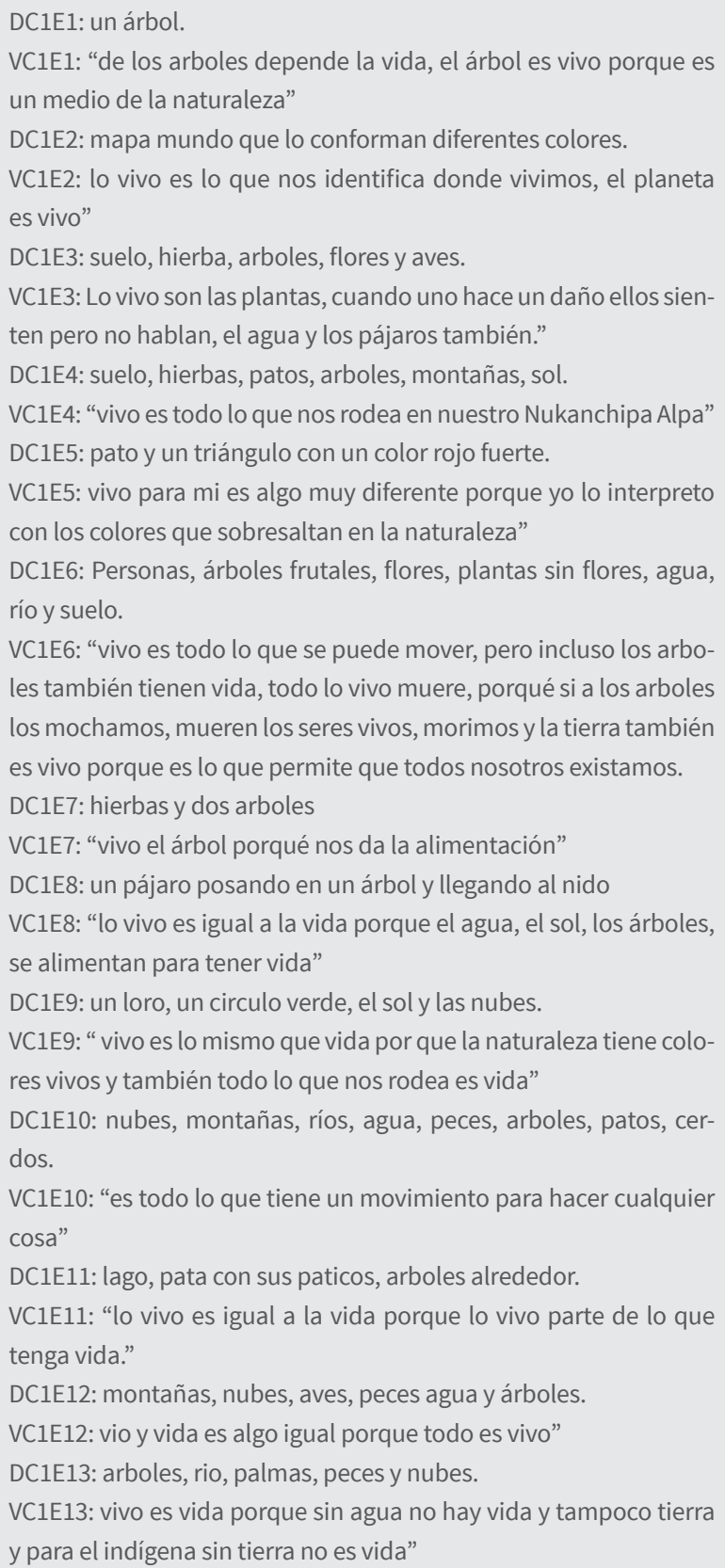 & $\begin{array}{l}\text { DSCE1: Palmas de chontaduro, plátano, yuca son } \\
\text { elementos que hacen parte de una Chagra ances- } \\
\text { tral. } \\
\text { VSCE1: la chagra ancestral tiene diferentes pro- } \\
\text { ductos que ayudan para poder vivir y dentro de } \\
\text { nuestras prácticas se tiene en cuenta el ciclo lunar. } \\
\text { DSCE2: una persona, con una rula que se dirige al } \\
\text { monte a plateary deshojar. } \\
\text { VSCE2: "Son las que hacemos, cotidianamente y } \\
\text { que nos sirven para el existir o para vivir". } \\
\text { DSCE3: Matas de plátano y la luna cuarto men- } \\
\text { guante. } \\
\text { VSCE3: en nuestras prácticas ancestrales tenemos } \\
\text { en cuenta la luna, de acuerdo a ella lo que sembra- } \\
\text { mos crece, por ejemplo en luna llena sembramos } \\
\text { plátano, Yuca, Names y otros" } \\
\text { DSCE4: una Chagra } \\
\text { VSCE4: las practicas ancestrales agrícolas, es } \\
\text { donde aprendemos desde la práctica, para poder } \\
\text { sobrevivir fortaleciendo el Nukanchipa Alpa. } \\
\text { DSCE5: Un hombre con una Rula y una Pala } \\
\text { cavando la tierra. } \\
\text { VSCE5: "En la agricultura inga tenemos en cuenta } \\
\text { las fases lunares para poder culminar una serie de } \\
\text { actividades en el Nukanchipa Alpa, con las prac- } \\
\text { ticas se aprende y se desaprende para cuidar el } \\
\text { territorio" } \\
\text { DSCE6: Chagra, abonos orgánicos, compostera, } \\
\text { ciclo lunar, sol y árboles y palmas de chontaduro. } \\
\text { VSCE6: "agricultura ancestral son todas las prac- } \\
\text { ticas que realizamos nosotros, por ejemplo } \\
\text { teniendo en cuenta la luna para hacer cada activi- } \\
\text { dad en el territorio" } \\
\text { DSCE7: Palmas de Chontaduro, Yuca, Bore, Plá- } \\
\text { danostestranales. }\end{array}$ \\
\hline
\end{tabular}

* DC1E1 (dibujo categoría 1, estudiante 1) y VC1E1 (Verbalización Categoría 1, estudiante 1); DSCE1 (dibujo subcategoría estudiante 1); VSCE1 (verbalización subcategoría estudiante 1). 


\begin{tabular}{|c|c|c|}
\hline CATEGORIA & $\begin{array}{l}\text { UNIDADES DE INFORMACIÓN } \\
\text { (Representaciones Sociales) }\end{array}$ & $\begin{array}{c}\text { SUBCATEGORIA: } \\
\text { Relación Prácticas Agrícolas Ances- } \\
\text { trales }\end{array}$ \\
\hline 2. VIDA & 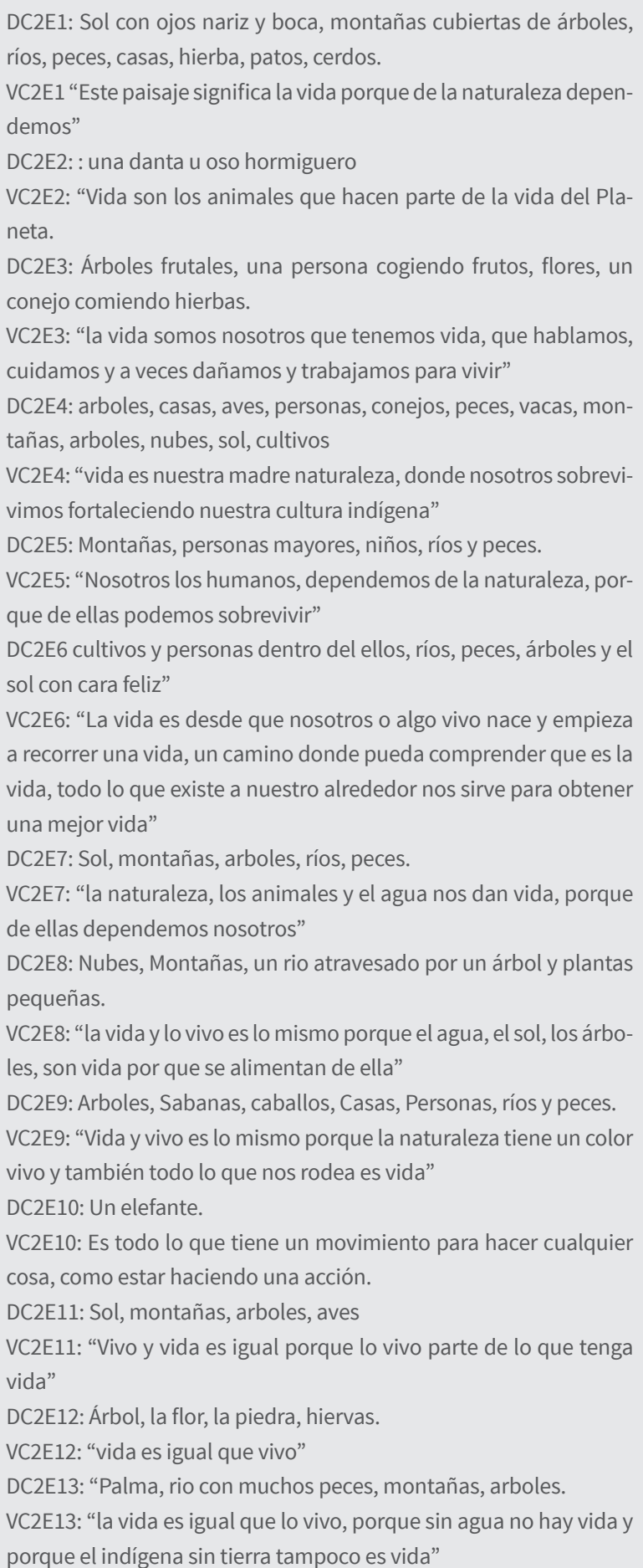 & $\begin{array}{l}\text { DSCE8: Plátano que se sembramos en la chagra. } \\
\text { VSCE8: "La agricultura es para los inga lo que sig- } \\
\text { nifica la vida el inga sin tierra no puede estar vivo" } \\
\text { DSCE9: Un hombre con una Rula en una chagra } \\
\text { limpiando el plátano, el bore, la yuca y las palmas } \\
\text { de chontaduro. } \\
\text { VSCE9: } \\
\text { "Las prácticas agrícolas ancestrales nos repre- } \\
\text { senta a como nosotros como Inganos conser- } \\
\text { vando las chagras y el Nukanchipa Alpa y a través } \\
\text { de nuestras Prácticas reproducimos las comidas } \\
\text { típicas y sembramos plantas medicinales para } \\
\text { sobrevivir". } \\
\text { DSCE10: Un hombre con una Rula limpiando y } \\
\text { deshojando una Palma de coco. } \\
\text { VSCE10: "las prácticas agrícolas nos permiten } \\
\text { tener un espacio donde nosotros podamos culti- } \\
\text { var nuestro alimento para poder vivir". } \\
\text { DSCE11: Una persona bajando cocos de una } \\
\text { palma con una media luna en horas de la mañana } \\
\text { VSCE11: "en las prácticas agrícolas y agricultura } \\
\text { ancestral se deben tener en cuenta la luna y el } \\
\text { tiempo para bajar los frutos no se pueden bajar } \\
\text { Cuando hay mucho sol" } \\
\text { DSCE12: una palma de Coco y una luna llena. } \\
\text { VSCE12: "las plantas se siembran en luna llena } \\
\text { para que no crezcan tanto y den buena produc- } \\
\text { ción" } \\
\text { DSCE13: Un cultivo de Palmas de chontaduro y } \\
\text { coco y las diferentes fases lunares. } \\
\text { sembremos en buena luna vamos a tener buena } \\
\text { producción para sobrevivir bien" }\end{array}$ \\
\hline
\end{tabular}

* DC1E1 (dibujo categoría 1, estudiante 1) y VC1E1 (Verbalización Categoría 1, estudiante 1); DSCE1 (dibujo subcategoría estudiante 1); VSCE1 (verbalización subcategoría estudiante 1). 
La matriz 2 muestra las mismas categorías de la matriz 1 , pero con la información recopilada de los mayores y orientadores de la institución. Los códigos de información para los mayores fueron: UIM1 (unidad de informa- ción mayor 1) y UIO1 (unidad de información orientador 1). Las actividades se realizaron con 3 mayores y 5 orientadores de la comunidad Ingakuna del Caquetá y se les pidió previa autorización para publicar sus nombres.

Tabla 2. Matriz de categorización de información de mayores y orientadores de la i.e Inga Yachaikury

\begin{tabular}{|c|c|}
\hline CATEGORIAS & $\begin{array}{l}\text { UNIDADES DE INFORMACIÓN } \\
\text { (Representaciones Sociales) }\end{array}$ \\
\hline VIVO Y VIDA & 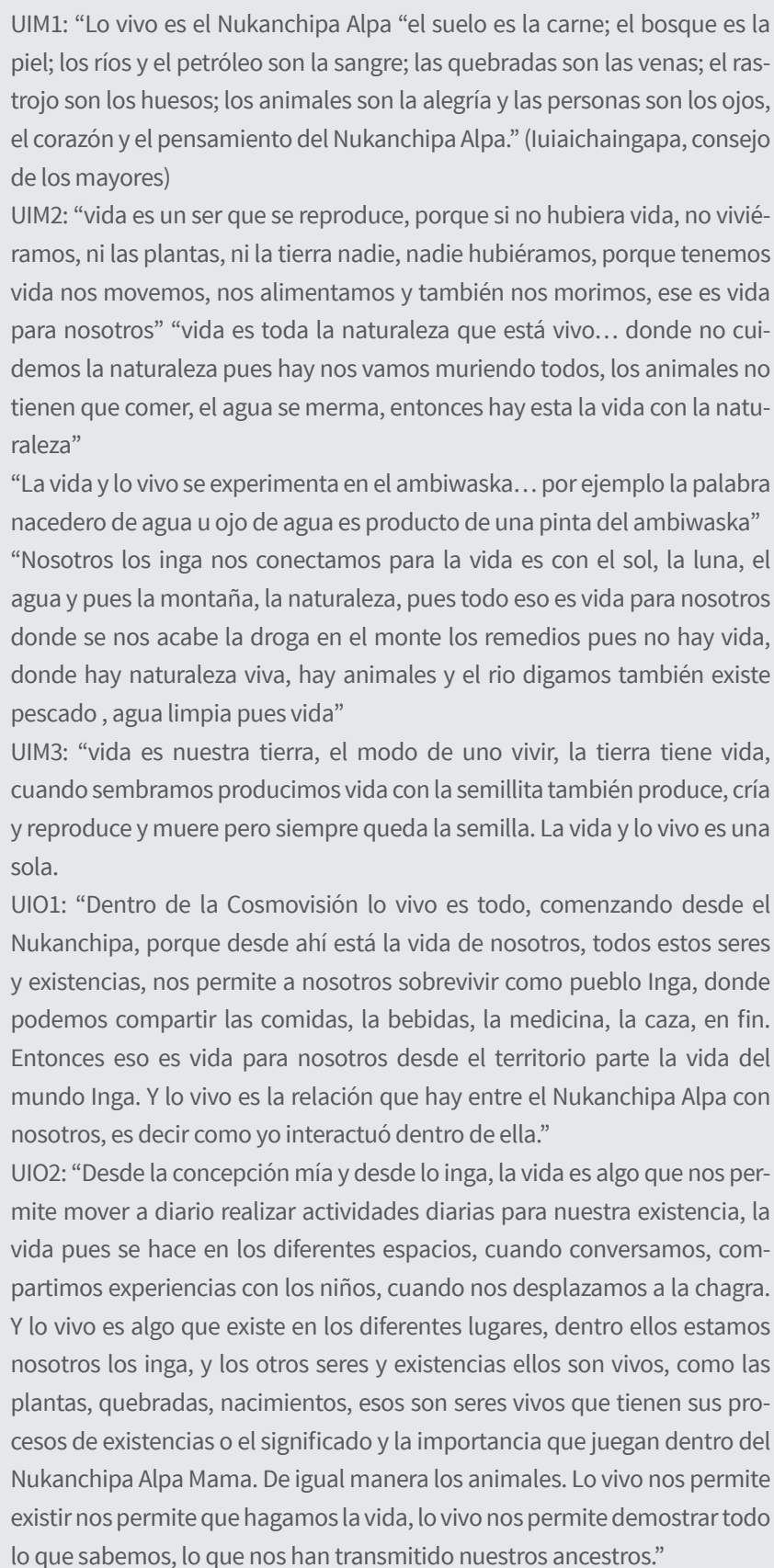 \\
\hline
\end{tabular}

\section{SUBCATEGORÍA: Prácticas Agrícolas Ancestrales}

UIM2: "la vida y lo vivo esta todo relacionado, digamos no es aparte, con los alimentos, como la yuca, pues comemos, pero la yuca es remedio para la erisipela, para los quebrados, el almidón, la yuca es remedio da vida"

UIM3: "Además en el ser humano es la misma cosa si nosotros cultivamos bien la tierra guardamos lo que hemos aprendido de nuestros padres no se va a acabar la vida. El indígena sin tierra no es vida, la tierra es la madre para dar producción, sostenimiento y alimentación, pero si trabajamos la tierra"

UIO1: "como yo voy cultivo dentro del territorio sin causarle daño, porque digamos si nosotros no partimos desde lo vivo, desde el pensamiento, según el luiachingapa dice que nosotros las personas somos el pensamiento, el corazón y los ojos, entonces de ahí parte la relación entre Nukanchipa y nosotros como seres vivientes"

UIO2: "lo vivo y la vida está directamente relacionado con el territorio, porque lo vivo es todo lo que hay en el Nukanchipa Alpa, pues ahí está la existencia de nosotros, las plantas medicinales, alimenticias, artesanales. Todo esto hace que nosotros realicemos nuestra vivencia, si no hubieran los otros seres y existencias de Nukanchipa no habría vida.

UIO3: la tierra tiene vida, porqué si nosotros utilizamos el Nukanchipa Alpa para una chagra pues sembramos la semilla entonces ella empieza a coger la vida entonces nosotros sembramos y cosechamos lo vivo para vida"

* Información obtenida por comunicaciones personales. UIM1: Taita Patricio Jojoa. UIM2: Mayora Natividad Mutumbajoy. UIM3: Mayora Antonia Mutumbajoy. UIO1: Evirley Mutumbajoy Díaz. UIO2: Wilmar Becerra. UIO3: Alex Becerra. UIO4: Yolanda Jacanamejoy. UIO5: Nelcy Méndez. 


\section{VIVO Y VIDA}

UIO3: "la vida es todo lo que no rodea, todos los elementos que tiene Nukanchipa Alpa que es el territorio, ahí encontramos las plantas, los animales, son vida, y ellos nos dan vida a nosotros y nosotros los tenemos que cuidar para tener buena vida. Y lo vivo es casi lo mismo pues todos los elementos que se necesitan de otros, como las aves necesitan de las frutas para estar vivas y las plantas que necesitan del agua de la luz.

UIO4: "es la tierra, porque la tierra es viva, es la que da fruto, igual como la persona que da vida, entonces entre esas tres cosas hay relación vida, vivo y tierra". La tierra tiene vida y se relaciona con lo vivo porque lo vivo se mueve, crece por eso es vivo. Y la vida es la creación que Dios creo al mundo, ahí donde estamos, el ser humano, los animales $Y$ esta todo lo más mínimo que no se ve se relaciona con ese ser vivo.

UIO5: ella, Lo vivo lo define como lo que se vive dentro y fuera de la comunidad, el trabajo en equipo, la medicina tradicional, la artística, las artesanías y la experiencia a través de ambiwaska. La vida es definida como el sustento diario, los cultivos, las comidas...

* Información obtenida por comunicaciones personales. UIM1: Taita Patricio Jojoa. UIM2: Mayora Natividad Mutumbajoy. UIM3: Mayora Antonia Mutumbajoy. UIO1: Evirley Mutumbajoy Díaz. UIO2: Wilmar Becerra. UIO3: Alex Becerra. UIO4: Yolanda Jacanamejoy. UIO5: Nelcy Méndez.

\section{Discusión}

"Los Inga nos conectamos para la vida con el sol, la luna, el agua, la montaña, la naturaleza, y todo eso es vivo para nosotros"

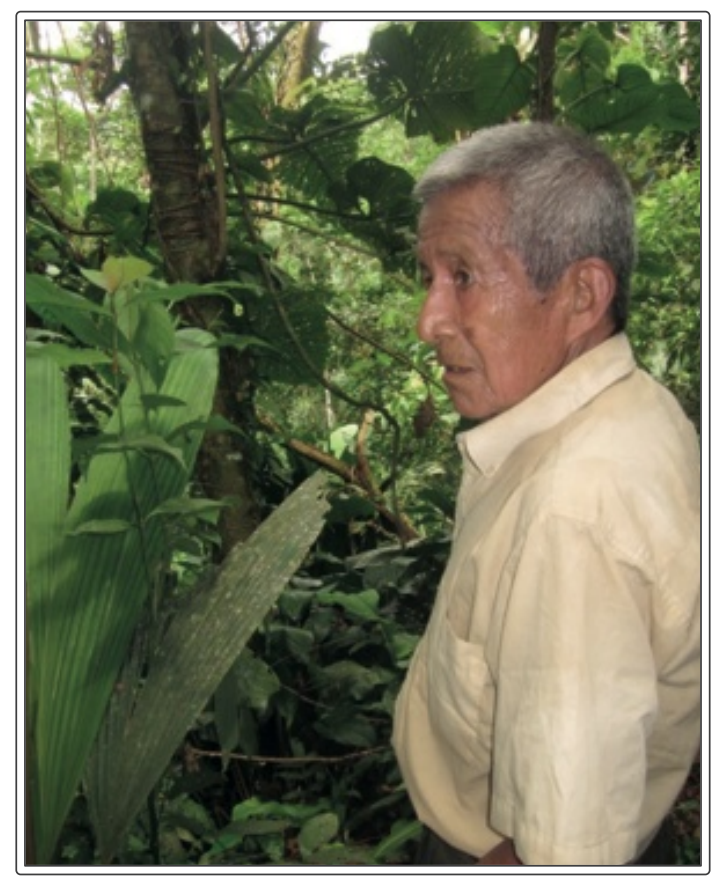

Fotografía 1. Médico tradicional. Sabedor Patricio Jojoa. Recorrido por el Nukanchipa Alpa Mamá.

Fuente: Fotografía, Mutumbajoy, 2013.
Teniendo en cuenta la información recopilada y el objetivo de la investigación, se identificaron aspectos importantes del saber inga y en él, un conjunto de conocimientos, creencias, actitudes y aptitudes para representar la vida y lo vivo como dos categorías unidas que no difieren en su significado, en la medida en que lo vivo para ellos parte de lo que tiene vida y la vida se cultiva y se labra en la chagra, incluyendo directamente a las prácticas agrícolas ancestrales como una manera de conservar el territorio y favorecer la vida.

Para el mayor P. Jojoa, Fotografía 1. (Comunicación personal, 5 de marzo de 2013), lo vivo es Nukanchipa Alpa y lo asemeja a una ser humano que tiene vida manifestando que:

El suelo es la carne, el bosque es la piel; los ríos y el petróleo son la sangre; las quebradas son las venas; el rastrojo son los huesos; los animales son la alegría y las personas son los ojos, el corazón y el pensamiento del Nukanchipa Alpa.

Estas palabras hacen parte del luiaichaingapa o consejo de los mayores, que es un eje importante en las actividades que realizan orientadores y estudiantes en el camino de aprenhendizaje. 
Queda claro, así como se plantea en el libro de Cunningham (2006, p. 15)

[Que la mayoría de] los pueblos indígenas sienten el mundo como la relación e interconexión de muchas partes, que se necesitan unas a otras. $Y$ los seres humanos somos una de esas partes, nadie en el mundo puede estar aislado o de hecho jamás lo está, siempre tienen lazos con los demás sean estos humanos o no, divinos, o no.

Las representaciones de los mayores hacen parte de una cosmovisión que para ellos es la propia idea e imagen del cosmos, la forma de pensar, ver y sentir el mundo y unas creencias que les permiten percibir la vida-vivo como algo que esta interconectado y que lo favorecen en la medida en que practican una agricultura ancestral conveniente que no dañe el territorio y les proporcione la supervivencia física y cultural de su pueblo.

Las palabras de la mayora Natividad, fotografía 2. (Mutumbajoy, comunicación personal, 23 de abril de 2013) confirman esta interpretación cuando manifiesta:

Nosotros lo Inga nos conectamos para la vida es con el sol, la luna, el agua y pues la montaña, la naturaleza, pues todo eso es vida para nosotros, donde se nos acabe la droga en el monte, los remedios, pues no hay vida, donde hay naturaleza viva, hay animales y en el rio digamos también existe pescado, agua limpia, pues es vida y la vida y lo vivo se experimentan a través del ambiwaska.

El ambiwaska o yagé, planta viva que les genera conocimiento, ideas, frases y palabras para entender y relacionarse con todo lo que observan; las prácticas de los rituales de ambiwaska, momentos centrales dentro de su cosmovisión construyen una relación especial entre el inga y Nukanchipa Alpa Mama y aportan al "desarrollo del pensamiento ancestral a través de la construcción de imaginarios colectivos y representaciones simbólicas, con miradas más allá de lo aparente, facilitando procesos de aprehendizaje y construcción de conocimiento" (Proyecto Etnoeducativo, 2012).

Para los orientadores las RS, parten de un proceso de construcción de conocimientos que son compartidos por los Ingakuna del Caquetá, porque su cosmovisión se enmarca en una actividad colectiva de construcción social de ideas, pensamientos y creencias que tienen una trascendencia histórica y social, además en su comprensión del mundo, se articulan un cúmulo de representaciones que cobran sentido con la práctica y la transmisión a las futuras generaciones. Esto se puede evidenciar en las palabras de la del profesor Evirley Mutumbajoy Díaz (comunicación personal, 29 de abril de 2013):
Dentro de la cosmovisión lo vivo es todo, comenzando desde el Nukanchipa, porque desde ahí está la vida de nosotros, todos estos seres y existencias, nos permite a nosotros sobrevivir como pueblo Inga, donde podemos compartir las comidas, la bebidas, la medicina, la caza, en fin. Entonces eso es vida para nosotros desde el territorio parte la vida del mundo inga. Y lo vivo es la relación que hay entre el Nukanchipa Alpa con nosotros, es decir como yo interactuó dentro de ella.

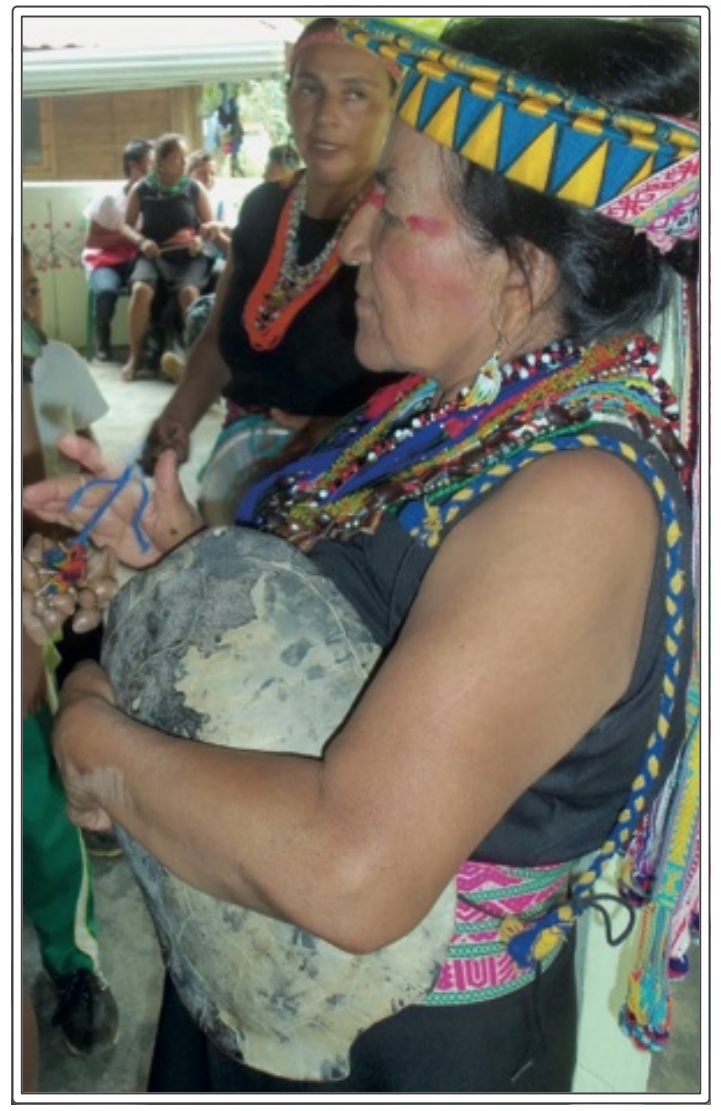

Fotografía 2. Mayora Natividad Mutumbajoy. Carnaval del perdón, Atun Puncha, 2013.

Fuente: Fotografía Cárdenas, 2013.

Y el profesor Wilmar Becerra (comunicación personal, 29 de abril de 2013) reafirma:

Desde la concepción mía y desde los inga, la vida es algo que nos permite mover a diario, realizar actividades diarias para nuestra existencia, la vida pues se hace en los diferentes espacios, cuando conversamos, compartimos experiencias con los niños, cuando nos desplazamos a la chagra, y lo vivo es algo que existe en los diferentes lugares, dentro ellos estamos nosotros los inga, y los otros seres y existencias 
ellos son vivos, como las plantas, quebradas, nacimientos, esos son seres vivos que tienen sus procesos de existencia o el significado y la importancia que juegan dentro del Nukanchipa Alpa Mama.

Estas definiciones se articulan con los principios que ordenan y mantienen en equilibrio el mundo en correspondencia con lo planteado por Cunningham (2006):

Los pueblos indígenas han sabido leer esos principios y es por esto que la naturaleza es armoniosa, esos principios son los elementos principales de una cosmovisión, primero todo está relacionado, todo se corresponde, todo se complementa y todo debe ser reciproco, cambian de nombre y en ciertas características de pueblo a pueblo pero se mantienen. (p. 47-56)

Los estudiantes son quienes están recibiendo los conocimientos de los mayores, orientadores de la comunidad, por ende tienen ideas, creencias, actitudes y aptitudes que provienen de sus abuelos y que han sido pasados en el proceso de aprendizaje. Dentro de la RS, se encuentran coincidencias en que para ellos la vida y lo vivo son lo mismo o son categorías dependientes en la medida en que lo vivo tiene vida.

Los argumentos de algunos estudiantes en los que dan una representación social de la vida y lo vivo son:

Vivo es todo lo que nos rodea en nuestro Nukanchipa Alpa; (Heraldo Becerra, estudiante de la IE Inga Yachaikury Comunicación personal, 13 de marzo de 2013)

Lo vivo es igual a la vida, porque el agua, el sol, los árboles se alimentan para tener vida; Freyner Mutumbajoy, estudiante de la IE Inga Yachaikury, Comunicación personal, 13 de marzo de 2013)

Lo vivo es igual a la vida porque lo vivo tiene vida; (Eduardo Mavisoy, Estudiante de la IE inga Yachaikury, Comunicación personal, 13 de marzo de 2013)

Y, vivo y vida es igual porque todo es vivo. Heraldo Becerra, estudiante de la IE Inga Yachaikury, Comunicación personal, 13 de marzo de 2013)

Se evidencia cómo se desarrolla un proceso educativo que se orienta y se configura con elementos vivos de la cultura inga, del luiaichingapa, del que hacer de los orientadores, y del mismo proceso de construcción de conocimiento del estudiante en relación a Nukanchipa Alpa, a la cosmovisión, a los saberes ancestrales y a la agricultura ancestral.

\section{"El indio sin tierra no tiene vida"}

En el proceso investigativo se encontró que existe una fuerte relación entre las representaciones sociales sobre la vida y lo vivo con la agricultura ancestral y sus prácticas, el estudio del saber inga acerca de lo vivo y de la vida, visto como RS, permite analizar aspectos puntuales que dan sentido a las prácticas agrícolas ancestrales y al cuidado de Nukanchipa Alpa, siendo este más que el espacio físico que ocupan, un espacio espiritual del que forman parte y recrean, orientados por la certeza de su cuidado y protección, lo que da unidad, enlaza, comunica y conecta todas las actividades para la supervivencia física, cultural y biológica de este pueblo. (Proyecto Etnoeducativo, 2012)

A continuación se muestran algunas representaciones de mayores, orientadores y estudiantes que enmarcan la conexión entre vivo-vida y prácticas agrícolas ancestrales.

Si nosotros cultivamos bien la tierra guardamos lo que hemos aprendido de nuestros padres no se va a acabar la vida. El indígena sin tierra no es vida, la tierra es la madre para dar producción, sostenimiento y alimentación, pero si trabajamos la tierra. (Antonia Mutumbajoy Díaz, Alcaldesa, resguardo San Miguel, Comunicación personal, 19 de abril de 2013).

Como yo voy y cultivo dentro del territorio sin causarle daño, porque digamos si nosotros no partimos desde lo vivo, desde el pensamiento, según el luiachingapa dice que nosotros las personas somos el pensamiento, el corazón y los ojos, entonces de ahí parte la relación entre Nukanchipa y nosotros como seres vivientes. Evirley Mutumbajoy Díaz, Orientador y Coordinador del Plan de Vida, Comunicación personal, 29 de abril de 2013)

La tierra tiene vida, porque si nosotros utilizamos el Nukanchipa Alpa para una chagra pues sembramos la semilla entonces ella empieza a coger la vida entonces nosotros sembramos y cosechamos lo vivo para vida. Wilmar Becerra, Gobernador reguardo Yurayaco y Docente de la IE Inga Yachaikury, (Comunicación personal, 29 de abril de 2013)

Es la tierra, porque la tierra es viva, es la que da fruto, igual como la persona que da vida, entonces entre esas tres cosas hay relación vida, vivo y tierra. La tierra tiene vida y se relaciona con lo vivo porque lo vivo se mueve, crece por eso es vivo. Wilmar Becerra, Gobernador reguardo Yurayaco y Docente de la IE Inga Yachaikury, (Comunicación personal, 29 de abril de 2013) 
Las prácticas ancestrales agrícolas, es donde aprendemos desde la práctica, para poder sobrevivir fortaleciendo Nukanchipa Alpa Mama. Eduardo Mavisoy, Estudiante de la IE inga Yachaikury, (Comunicación personal, marzo 13 de 2014)

La agricultura es para los Inga lo que significa la vida el Inga sin tierra no puede estar vivo. Darwin Queta Jacanamejoy, Estudiante de la IE inga Yachaikury, (Comunicación personal, marzo 13 de 2014).

Las prácticas agrícolas ancestrales nos representan a como nosotros como Ingakuna, conservando las chagras y el Nukanchipa Alpa y a través de nuestras Prácticas reproducimos las comidas típicas y sembramos plantas medicinales para sobrevivir. Eduardo Mavisoy, Estudiante de la IE inga Yachaikury, (Comunicación personal, marzo 13 de 2014)

De esta manera se infiere que la vida-vivo para el indígena inga es poder trabajar la tierra como un elemento vivo, del territorio que le proporciona el sustento y una posibilidad de pervivir física, cultural y biológicamente en el mundo de hoy. Con los dibujos que realizan los estudiantes y sus argumentos y en las palabras de mayores y orientadores, se puede interpretar que los conocimientos que ellos tienen se han transmitido y se siguen transmitiendo a través de la práctica y mediante el lenguaje oral y gestual y no es frecuente la comunicación escrita alfabéticamente, como sí lo es para la transmisión del conocimiento científico y en las culturas occidentales. La importancia de estos saberes o representaciones sociales es que además de ser procesos ancestrales de conocimiento, eje transversal para la supervivencia, son válidos para los Ingakuna y sus descendientes que los comparten, los recrean y con ellos expresan una forma de ser, de pensar y de estar en el mundo.

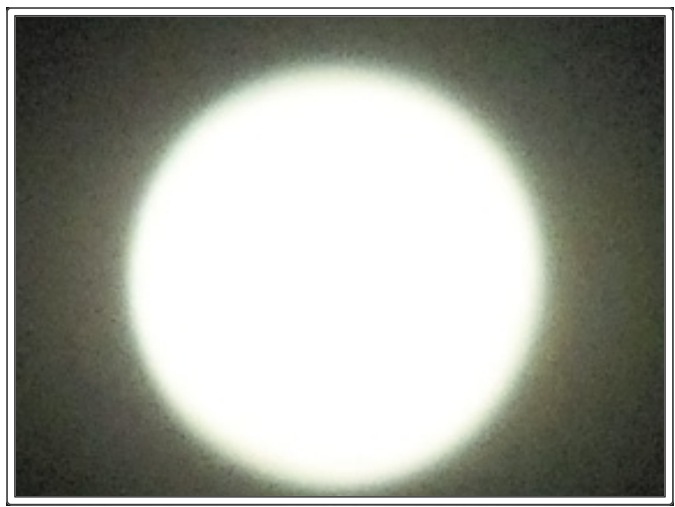

Fotografía 3. Luna Menguante. En esta luna "se siembra las matas como frutales y hortalizas por que crecen poco y se abona las plantas por que se fortalece el suelo" (Consejo mayores, Mutumbajoy, 2013)
Las prácticas agrícolas ancestrales para esta comunidad se refieren a los conocimientos y actividades desarrolladas por ellos a través de la historia que les permiten comprender y manejar sus propios ambientes locales, su territorio, se trata de un conocimiento práctico y no codificado ni estandarizado, es decir que no parten de un manual o una guía para el trabajo en las chagras, sino que parten del consejo de los mayores y de lo que han aprendido de sus abuelos de generación en generación, articulándolo con el conocimiento de las otras culturas. El arte y práctica del trabajo en el territorio y en la misma tierra se ha desarrollado por la observación directa y la experiencia que les permite conservar el saber ancestral de su etnia, el Nukanchipa Alpa como base de la vida y pasarlo a las siguientes generaciones, labor que están intentando realizar en su proceso de educación en Yachaikury.

Estas prácticas de siembra, cosecha y cuidado de los cultivos en la chagra están orientados por los calendarios solares y lunares, Ver fotografía 7, a diferencia de otras formas de conocimiento, este es culturalmente específico y está basado en las estrategias de vida que fundamentan el contexto y la realidad social de los Ingakuna del piedemonte amazónico.

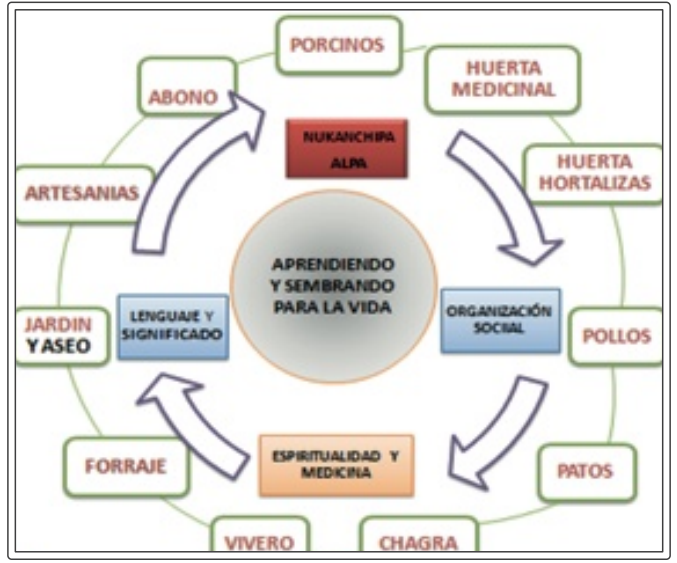

Gráfico 3. Esquema general de los proyectos pedagógicos: Aprendiendo y sembrando para la vida -lachaikuspa TarpuspaKaugsaimanda-. (Orientadores Inga, 2013).

Estas prácticas se combinan con otros conocimientos como los agro-ecológicos, que permiten desarrollar una interculturalidad en la medida en que se valoran otras formas de conocimiento y se ponen en condiciones de horizontalidad y que como propone García Canclini (2004), se remiten a la confrontación y el entrelazamiento cuando los grupos entran en relaciones de intercambio, implicando que los diferentes son lo que son en relaciones de negociación, conflicto y préstamos recíprocos. 
En el proceso educativo dentro de la institución se desarrolla una granja donde se manejan 14 proyectos agropecuarios, como se observa en el gráfico 3, estos proyectos son apoyados por promotores de la escuela agroecológica S.O.S, en estos se conjugan las prácticas ancestrales con los otros conocimientos y son los estudiantes quienes responden por estas actividades asociadas a los proyectos que articulan con el desarrollo de cada uno de los ejes, convirtiéndose en posibilidades pedagógicas para los estudiantes en el desarrollo de habilidades y destrezas para el trabajo en el territorio y como una estrategia de los orientadores para recuperar el sentido comunitario y las técnicas tradicionales de la agricultura Inga. lachaikuspa Tarpuspa Kaugsaimanda (aprendiendo y sembrando para la vida) es una forma de proyectarse como comunidad inga, surge de la necesidad de recrear las prácticas agrícolas y pecuarias de nuestros ancestros, y a su vez busca a fortalecer las prácticas pedagógicas de los maestros de la institución Yachaikury, al retomar estos lugares como espacios de aprendizaje desde los diferentes ejes.

Los productos alimentarios de la comunidad provienen directamente de las fibras naturales y de las materias primas que produce la Madre Tierra -Nukanchipa Alpa Mama-. El agua que toman y el aire que respiran están ligados a los ciclos naturales, con gran dependencia de la capacidad productiva de los suelos, están condicionadas por la diversidad de organismos y de los contenidos de materia orgánica y minerales. Todos son factores relacionados que hacen posible la vida del hombre en el territorio -Nukanchipa Alpa-, "es gracias a nuestro territorio que somos y estamos vivos" ${ }^{13}$, allí recrean sus prácticas y costumbres, este es un motivo para generar actitudes de respeto, valoración, conservación y aprovechamiento del territorio.

El proceso formativo está basado en el desarrollo de los proyectos donde los estudiantes adquieren destrezas, habilidades y competencias para un manejo de los recursos provenientes del territorio desde una perspectiva sostenible y de protección ambiental proponiendo alternativas al mejoramiento de la calidad de vida de la población Inga. La granja es una estrategia metodológica e investigativa para que el estudiante intercambie, innove y profundice los conocimientos a través de las realidades de la Alpa Mama, la conservación de los seres y existencias del territorio y la diversidad cultural, desde la granja se busca fortalecer el plan de vida, a través de objetivos globales como la conservación, la cultura y la salud, que apuntan al fortalecimiento de Nukanchipa Alpa Mama y la defensa del territorio.

\section{"Yachaikury es un camino donde todos desa- prendemos para aprender"}

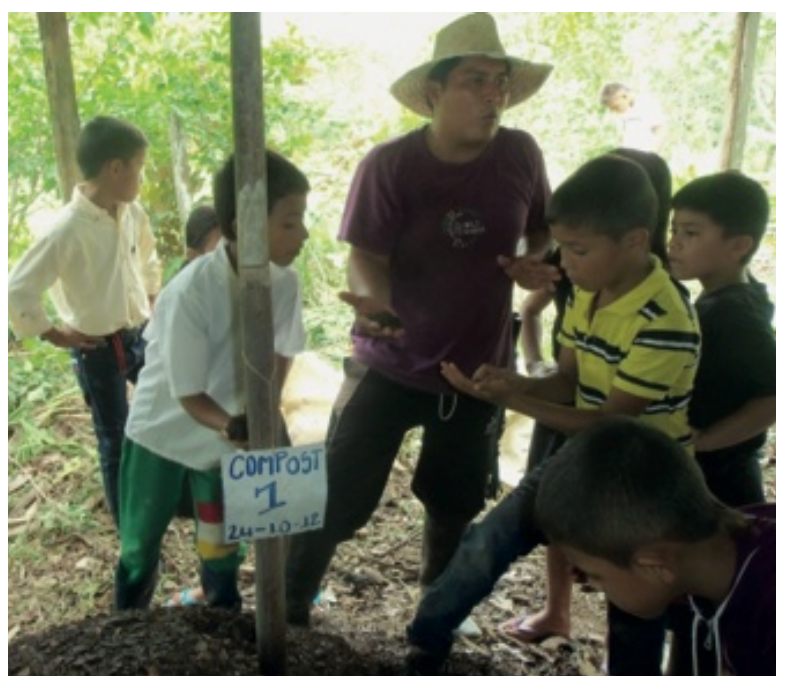

Fotografía 8. Clase de Nukanchipa Alpa, ciclo II. Reconocimiento de los principales animales descomponedores de la tierra.

Proyecto abonos orgánicos. Fotografía, (Cárdenas, 2013).

El consejo de Fals Borda a los docentes es que sigan inventando maneras de llegar a otras realidades, que entren en el detalle de las culturas, que aprendan de las realidades propias, que hay que saberlas distinguir, saberlas analizar, saberlas amar, y esas realidades están totalmente fuera de los esquemas educativos tradicionales y clásicos.

Tomo esta frase para realizar el análisis y la reflexión del proceso investigativo desarrollado en la práctica pedagógica, estas palabras enmarcan y definen el contexto del lugar en el que se desarrolló la experiencia. La Institución Educativa Inga Yachaikury representa una realidad educativa diversa e interesante, que lleva a cabo un proceso de educación propia, que parte desde su cosmovisión, sus conocimientos, el saber inga, representado por las prácticas que llevan a cabo para la supervivencia, física, cultural y biológica de su etnia y de su territorio, en fin, una realidad para distinguir, para analizar, para aprender y lo más importante que se esfuerza por superar prácticas que reproducen los sistemas tradicionales y clásicos de enseñanza.

El tipo de escuela que aquí se nos presenta es totalmente innovadora y contextualizada, parte de un trabajo en equipo y comunitario y unas necesidades que responden a una forma de ver y sentir el mundo en armonía e interconectado para la vida y en la vida. 
Según Prieto y Gutiérrez, citado por Reyes Pabón, "una educación desde este enfoque permite la movilización del pensamiento, es decir educar para la significación, para la expresión, para convivir, para apropiarse de la historia y la cultura, educar para la incertidumbre, para gozar la vida" (p. 4).

El proceso de aprendizaje es transversal, este rompe y atraviesa los planes de estudio, las disciplinas, los grados y niveles, la fragmentación del conocimiento; superando la educación tradicional y el denominado currículo oculto, donde aparecen antivalores propios de la educación hegemónica, como el individualismo, la competencia y el autoritarismo.

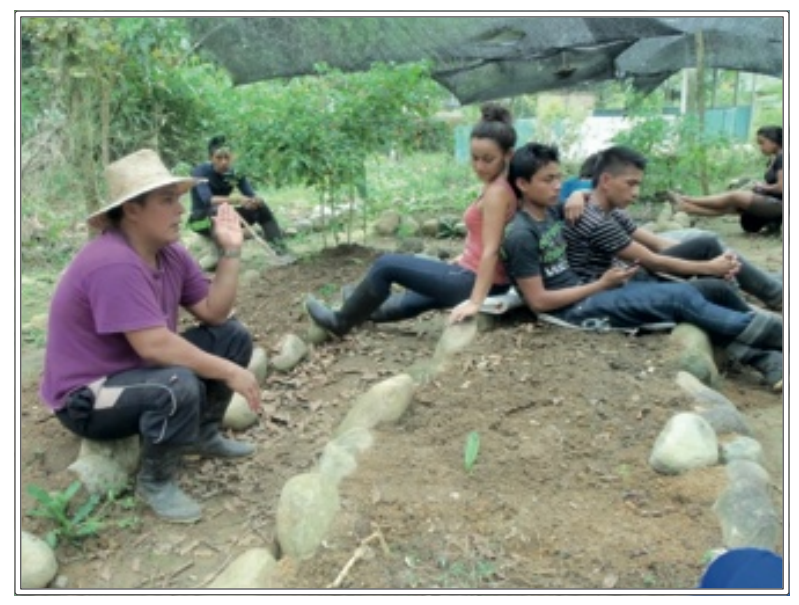

Fotografía 9. Desarrollo de una clase en la IE Inga Yachaikury. Proyecto Huerta, Clase del eje Nukanchipa Alpa. (Fotografía Cárdenas, 2013)

Aunque no existe un currículo establecido, se podría hablar de una metodología donde se desaprende en equipo para aprender, promoviéndose valores alternativos, donde las diferencias y las múltiples miradas del mundo son vistas como riquezas de todo grupo humano (Fuentes, 2002), donde se valora lo propio y también los otros conocimientos, donde los orientadores están abiertos a escuchar y aprender del otro en igualdad de condiciones. Esta afirmación se puede contrastar con uno de los pilares más importantes que valoran al sujeto y lo sacan de esa ola homogeneizadora y reprimente, la intersubjetividad, que según Hinkelammert (1999), es la única opción de darle vuelta al sujeto reprimido y aplastado por la modernidad, la liberación que recupera el ser humano como sujeto a través de esta condición, la intersubjetividad, es decir, "el hombre no es una instancia individual, incluye a la propia naturaleza externa del ser humano, y que el otro viva, es condición de la propia vida" (Hinkelammert, 1999, p. 10).
Pensar en la reconfiguración de la enseñanza de la biología, a partir de la comprensión de las diversas manifestaciones de la vida y de lo vivo, se presenta como un reto para este contexto y esta realidad educativa, donde es claro que la biología como disciplina no se encuentra fundamentada en este tipo de escuela, sin negar que existen lógicas y formas en que la comunidad inga construye e interpreta su mundo, los fenómenos que le rodean y procesos biológicos que surgen en cada momento, con cada actividad en la chagra, en la montaña, con el proyecto agropecuario, con la clase de medicina tradicional, en cada eje y proyecto de la granja, en el recorrido territorial, en las mingas y demás actividades que hacen parte del proceso de aprendizaje.

Los procesos educativos en esta comunidad son permanentes, como se observa en la fotografía 11 y 12, se educa en cada momento y lugar, todos tienen la palabra desde los conocimientos y la ignorancia, todos se equivocan y el error es una oportunidad para aprehender, todos tienen la responsabilidad de propiciar y aprovechar los espacios de aprendizaje de su cultura y de otras. (Modelo Etnoeducativo, 2013, p. 4)

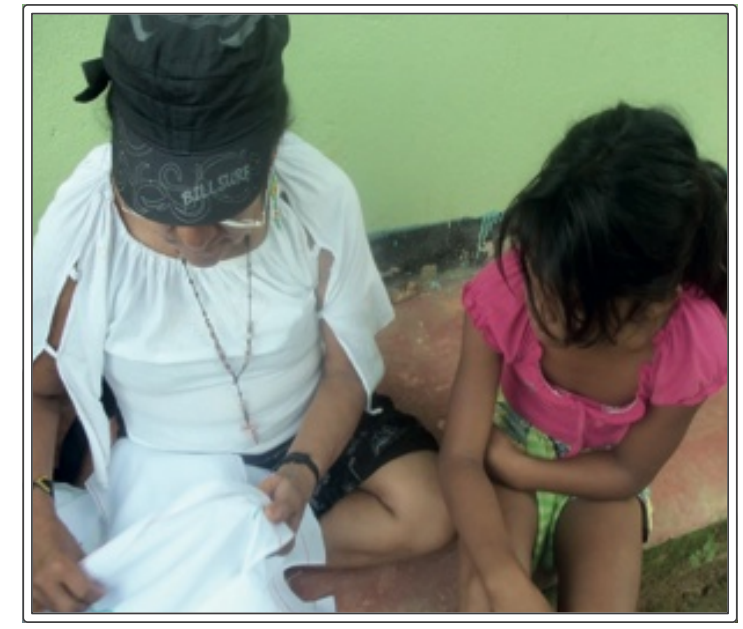

Fotografía 11. Taller de Bordado de Cusma (traje típico del hombre Inga). Fotografía. (Cárdenas, 2013)

El conocimiento se construye de manera colectiva y busca orientar y fortalecer su espiritualidad, sus prácticas y saberes ancestrales para el respeto del Nukanchipa Alpa Mama, que es fuente de vida, es el lugar donde se aprende y es la fuente de sabiduría.

Nuestros caminos de aprehendizaje se construyen desde nuestras formas particulares de recorrer la vida como cultura inga, son diversos, están en permanente construcción, se recrean en el pensamiento 
y la sabiduría de Nukanchipa Alpa Mama, de nuestros sinchikuna, iachagkuna o médicos inga, se expresa en las múltiples relaciones que construimos con el territorio como unidad que se afecta recíprocamente. [...] El conocimiento se debe sembrar, por eso el que no tiene historia, un canto propio, no puede sembrar. En el sembrar, no se puede separar el conocer del saber, sólo así se puede transmitir la energía, el espíritu del conocimiento. Una vez sembrado se debe activar, poner a prueba en el hacer, por ello en el conocimiento sentir, pensar, hacer, son complemento. (Modelo Etnoeducativo, 2013, p. 4)

En cuanto a las representaciones sociales de lo vivo y de la vida, enmarcadas en el saber inga se relaciona con lo que para ellos el sentir, el hacer, el pensar y el conocer así:

\begin{abstract}
Relaciones entre sentir - luiachiuai chaiaispa- o quedar -samai- quieto, que pasa como un aire por mi cuerpo, por mis venas, no se ve, se siente en el espíritu, en el interior y se desata para el hacer, estado que da apertura al conocer -Rigsii-, saber - lachai-y pensar -luiai-. La persona -runa- puede conocer y saber, alguien sabe porque lo ha vivido, lo ha conocido, lo ha andado; o sabe, porque otro se lo ha contado, se lo hizo saber. Y el pensar es como la lanzadera del tejido, lo que lo conduce a uno por ese camino de conocimiento, relacionando, tramando. El consejo de nuestros mayores es: vivir pensando, saber ver, prevenir para actuar o decir, no andar llamando cosas que no se deben estar trayendo! (Modelo Etnoeducativo 2013. P., 8).
\end{abstract}

Así es que se construyen sus representaciones, parten de lo que creen, de lo que hacen, de lo sienten y viven a diario y así lo convierten en conocimiento, el conocimiento que siembran, que es propio, que conocen y que por esa razón está unido y hace parte del saber, son dos categorías inseparables que se ponen a andar en el hacer, la práctica que es su eje transversal para el aprehendizaje y que les permite manifestar la forma de ver, sentir, pensar y conocer el mundo.

\section{Conclusiones}

Las Representaciones Sociales (RS) de los mayores, orientadores y estudiantes de la Institución Inga Yachaikury sobre la vivo y la vida, corresponden a todos los conocimientos, creencias, actitudes y aptitudes que poseen para representar dichas categorías en sus quehaceres diarios, en el proceso educativo, en el trabajo en la chagra, en el río y en su territorio que es la fuente de vida de esta comunidad.
Lo vivo y la vida para esta comunidad en términos semánticos es igual, pues ambos términos para la mayoría de los actores no difieren en su significado y se corresponden en la medida en que para ellos lo vivo parte de lo que tiene vida y la vida se cultiva y se labra en la chagra. La metáfora con que el sabedor o taita de la comunidad define el territorio -Nukanchipa Alpa- es un buen ejemplo de la interconexión porque se infiere que las dos categorías de estudio dependen una de la otra y en tanto se afecte una la otra también resultara afectada. Las representaciones de los mayores hacen parte de una cosmovisión que para ellos es la propia idea e imagen del cosmos, la forma de pensar, ver y sentir el mundo y unas creencias que les permiten percibir la vida y lo vivo como algo que esta interconectado y relacionado, estas representaciones están enmarcadas en el sentir, el hacer, el pensar y el conocer.

Las prácticas agrícolas ancestrales en el territorio permiten identificar representaciones sociales de lo vivo y de la vida, pues en sus discursos son definidas como la manera para conservar el territorio y favorecer la vida, pues la comunidad se conecta con la vida a través de sol, la luna, el agua, y las montañas donde crece el alimento, la medicina, el remedio - ambiwaska-. La vida y lo vivo para el indígena inga es poder trabajar la tierra como un elemento vivo, del territorio que le proporciona el sustento y una posibilidad de pervivir física, cultural y biológicamente en el mundo de hoy.

El ambiwaska o yagé es la planta que les genera conocimiento para entender y relacionarse con todo lo que observan a través de sus ceremonias, momentos centrales dentro de su cosmovisión donde construyen una relación especial entre el inga y Nukanchipa Alpa Mama, a través de imaginarios colectivos y representaciones simbólicas para entender los fenómenos que les rodean y facilitar los procesos de enseñanza y aprendizaje a través de la práctica.

Las RS de los estudiantes muestran que existe una correspondencia entre los que saben, piensan, creen y hacen los mayores y orientadores de la institución, pues son quienes están recibiendo los conocimientos en el proceso educativo que se lleva en la institución, y consideran que para ellos la vida y lo vivo no son categorías separadas y son dependientes una de la otra.

La interpretación de las RS, desde la perspectiva hermenéutica permitió entender al maestro en formación la importancia de interpretarse a sí mismo en un primer momento como punto de partida para interpretar la realidad del otro y comprenderla, pues es claro que todas las realidades son cambiantes y los contextos diversos, y 
siguiendo a Guber, (2005), en la medida en que el investigador forma parte de "la realidad del sujeto de conocimiento se resignifica y encuentra un nuevo lugar" (p. 45) para comprender y explicar las situaciones.

El trabajo con las RS en el ámbito escolar del pueblo Ingakuna del Caquetá permite al docente en formación considerarlas como una manera de reconocimiento y una oportunidad para generar cuestionamientos acerca del rol del docente en un contexto educativo donde se construye el conocimiento de otra manera, cuál sería su papel en una experiencia colectiva donde se aprende en la enseñanza, o si el maestro sabe, conoce, hace y/o piensa en cómo generar estrategias para que se logre un aprendizaje que responda a las características propias de una determinada comunidad desde una plataforma intercultural que permita entender la realidad del otro, reconocerla y favorecer diálogo horizontal en condiciones de igualdad.

La práctica pedagógica generó aportes al docente en formación en la medida en que desarrolla habilidades en el reconocimiento de los modos y procesos de constitución del pensamiento de la comunidad inga del Caquetá, de la escuela y del rol de maestro, para interpretar la realidad biológica que viven, además de la aproximación a lo vivo y la vida que tienen los actores principales de este contexto y cómo desde el conocimiento ancestral, que tienen proyectan acciones políticas, económicas, en síntesis de vida, en su relación mayoritaria y el Estado.

\section{Referencias}

Araya, S. (2002). Las representaciones sociales: ejes teóricos para su discución. Costa Rica: Facultad Latinoamericana de Ciencias Sociales. Recuperado el día 12 septiembre de 2011 de http://unpan1. un.org/intrad006Fdc/groups/public/documents/ ICAP/UNPAN027076.pdf.

Asociación de Cabildos Tandachiridu Inganokuna. (s.f.). Tarpusunchi Kausay. Cartilla sembrando para la vida. Colegio Inga Yachaikury.

Departamento de Biología. (2012). Proyecto curricular Licenciatura en Biología. Bogotá.

Castaño, N. (2010). Enseñanza de la biología, en un país biodiverso, pluriétnico y multicultural. Aproximaciones epistemológicas. Revista Bio-grafía, 511-538.
Fuentes, N. (2002). Educación ambiental, educación popular o simplemente educación. Buenos Aires. Recuperado el día 10 de septiembre de 2011 de: http://cesa-gjp.ning.com/page/educacion-ambiental-educacion?xg_source=activity.

García Canclini, N. (2004). Diferentes, desiguales y desconectados: Mapas de la interculturalidad. GEDISA. Barcelona, España.

Guber, R. (2005). El metropolitano salvaje: Reconocimiento del conocimiento social en el trabajo de campo. Barcelona: Paidós.

Hinkelammert, F. (1999). Sujeto y Globalización. Utopía y praxis latinoamericana: revista de filosofía.

Ministerio de Educación Nacional (men) (2009). Colombia-aprende. Educar en la diversidad y para la diversidad. Colombia.

Ministerio de Educación Nacional (men) (2012). Proyecto Etnoeducativo del Pueblo Inga: Así caminamos con nuestros saberes -Kasami purinchi nukanchipa iachaikunawa-. Bogotá D.C

Ministerio de Educación Nacional (men) (2012-2013). Modelo Etnoeducativo del Pueblo Inga. Nukanchipa atun iachachii ñambikuna. Bogotá D.C.

Monzón, L. (2011). La identidad docente desde una perspectiva de la hermenéutica. Revista Educación y desarrollo. México. Recuperado el día 18 de febrero de 2014, de: https://www.academia.edu/525937/ La_identidad_docente_desde_una_perspectiva_ hermeneutica.

Nuñez, J. (2004). Formación docente y saberes locales:una mirada desde la ruralidad. Revista Digital y Rural: Educación Cultura y Desarrollo Rural. Recuperado el día 3 de agosto de 2012 de: http:// www.red-ler.org/formacion-docentes-saberes-locales.pdf.

Prieto, D. y Gutiérrez, F. (1996). Sentir lo alternativo. Revista Aportes, 41.

Reyes Pabón, C. (s.f.). Reflexiones sobre el quehacer pedagógico. Red Académica. Recuperado el día 20 de junio de 2012, de: http://www.uhu.es/36102/ trabajos_alumnos/pt1_11_12/biblioteca/3modelos_didacticos/quehacer_pedagogico.pdf.

Rodríguez, G., Gil, J. y García, E. (1996). Introducción a la Investigación cualitativa. Archidona: Ediciones Aljibe, España.

Rodríguez, O. (2007). Rituales en La Ultra Morada: la máscara de la pertenencia. Revista Centroamericana de Ciencias Sociales, IV(1), 209-252. 